\section{NOVA TELLVS}

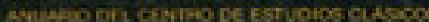

Nova Tellus

ISSN: 0185-3058

novatelu@servidor.unam.mx

Centro de Estudios Clásicos

México

Rojas Álvarez, Lourdes

La novela griega: en busca de lo maravilloso y extraordinario

Nova Tellus, vol. 27, núm. 1, 2009, pp. 229-245

Centro de Estudios Clásicos

Distrito Federal, México

Disponible en: http://www.redalyc.org/articulo.oa?id=59115499008

- Cómo citar el artículo

- Número completo

- Más información del artículo

- Página de la revista en redalyc.org

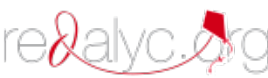

Sistema de Información Científica

Red de Revistas Científicas de América Latina, el Caribe, España y Portugal

Proyecto académico sin fines de lucro, desarrollado bajo la iniciativa de acceso abierto 


\title{
La novela griega: en busca de lo maravilloso y extraordinario
}

\author{
Lourdes RoJAs ÁlVAREZ \\ Universidad Nacional Autónoma de México \\ lourdes_rojasa@hotmail.com
}

RESUMEN: En este trabajo se aborda la presencia de lo maravilloso y extraordinario en la novela griega denominada erótica. Partiendo de un breve esbozo sobre los distintos tipos de novela, y la relación que la literatura tiene con la sociedad en que se produce, se aborda la cuestión de la innovación como componente de las obras literarias, por influencia de la Segunda Sofística. En la novela erótica la originalidad de cada obra se basa en la confección de las aventuras donde el autor inserta toda clase de elementos, incluidos los de carácter extraordinario (paradoxon). Se ejemplifica con pasajes de Longo, Aquiles Tacio y Jenofonte de Éfeso.

$$
* * *
$$

ABSTRACT: The present communication deals with the presence of the marvelous and extraordinary in the Greek romances, classified as erotic. We include a brief survey of the different types of romances, and the relationship that literature has with the society in which it is produced. Then we treat the matter of innovation as a component of literary pieces, as an influence of the Second Sophistic. In the erotic romance the originality of each one is based on the confection of adventures where the author inserts all kind of elements, including those of an extraordinary (paradoxon) character. We exemplify with passages of the works of Longus, Achilles Tatius and Xenophon Ephesius.

PALABRAS CLAVE: extraordinario, maravilloso, novela griega antigua, paradoxografía.

KEYWORDS: ancient greek novel, extraordinary, paradoxography, wonderful.

RECEPCIÓN: 23 de marzo de 2009.

ACEPTACIÓN: 27 de abril de 2009. 


\title{
La novela griega: en busca de lo maravilloso y extraordinario
}

\author{
Lourdes ROJAS ÁlVAREZ
}

La novela griega surge en los albores del Imperio Romano, hacia el siglo I d. C., y, como nuestra novela moderna, presenta distintas facetas.

Designamos como novela - término procedente del latín novella: relato novelesco - a una obra en prosa en la que se narra una acción fingida en todo o en parte, y cuyo fin es causar placer estético a los lectores con la descripción o pintura de sucesos o lances interesantes, de caracteres, de pasiones y de costumbres. ${ }^{1}$

Las denominaciones de la novela varían en función de la materia fundamental que constituye su argumento, y así se habla de distintos tipos de novela: bizantina, de aventuras, que se desarrolló en España principalmente en los siglos XVI y XVII, a imitación de autores helenísticos; gótica, variedad de relato de misterio y terror que aparece a finales del siglo XVIII; histórica, la que desarrolla su acción en épocas pasadas, con personajes reales o ficticios; pastoril, en el Siglo de oro, la cual narraba las aventuras y desventuras amorosas de pastores idealizados; picaresca, cultivada en los siglos XVI y XVII, y que, normalmente en primera persona, relataba las peripecias poco honorables de un pícaro; y rosa, variedad de relato novelesco, cultivado en época moderna, con personajes y ambientes muy convencionales, en el cual se narran las vicisitudes de dos enamorados, cuyo amor triunfa frente a la adversidad.

\footnotetext{
${ }^{1}$ Cf. J. Huerta Calvo, en P. Aullón de Haro, 1994, pp. 155-161.
}

NOVA TELLVS, 27•1, 2009 
Pues bien, todas estas variantes y otras más estaban incluidas en la que nosotros denominamos novela griega, y que se conoce en otras lenguas como romance, pero que careció de denominación en la antiguiedad, seguramente en virtud de su

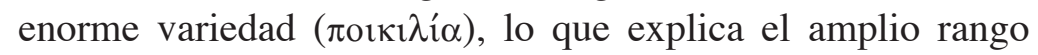

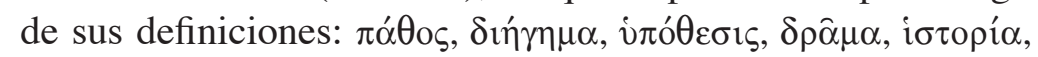
$\mu \hat{v} \theta$ os, $\tau \dot{\chi} \chi \eta$.

Tradicionalmente, las novelas griegas fueron clasificadas en dos grandes grupos:

1) Novelas serias o idealistas, a las que pertenecerían las denominadas novelas de amor y aventuras, entre las que se cuentan las de Caritón, Jenofonte Efesio, Aquiles Tacio, Longo y Heliodoro, y otra serie de fragmentos sacados a la luz de las arenas de Egipto, en Fayum y Oxirrinco, hacia 1899.

2) Las novelas cómicas o paródicas, como puede clasificarse a los fragmentos de Yolao, Las Fenicíacas de Loliano, y las novelas del Asno: Las Metamorfosis de Lucio de Patras y Lucio o El Asno, que constituyen un grupo junto con las novelas latinas de Petronio y Apuleyo.

Pero quedan fuera de esta clasificación otras novelas de carácter mixto, que generalmente han recibido la denominación de utópicas, como Las aventuras más allá de Tule de Antonio Diógenes, las Historias verdaderas de Luciano y la fragmentaria utopía de Jambulo; o los relatos biográficos, como La Vida de Alejandro, Vida de Esopo y Vida del filósofo Segundo. También hay que incluir a la denominada novela epistolar, entre la que se cuenta las Cartas de Quión de Heraclea o las apócrifas Actas de Pablo y Tecla, títulos que hacen ver la enorme variedad de las novelas griegas antiguas, que se despliegan en un abanico temporal muy amplio, desde el siglo I a. C., hasta probablemente el siglo IV d. C., sin contar aquí a las novelas de época bizantina.

Como señalé anteriormente, no hubo un término antiguo para designar a la novela y los propios autores del género lo definen de manera variada. 
Caritón, el autor de la que es considerada la primera novela de amor y aventuras, Quéreas y Calírroe, habla de su obra

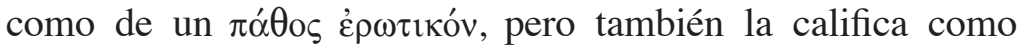
un $\theta \dot{\varepsilon} \alpha \tau \rho o v$ y se equipara a un poeta dramático, con toda justicia, como veremos más adelante. Estos conceptos también se encuentran en otros novelistas. Longo, por su parte, clasifica a su novela como $\mu \hat{v} \theta$ os.

Estrabón menciona que los $\mu$ v́⿴or, los relatos, no sólo fueron utilizados por los poetas, sino que también los legisladores se valieron de ellos por considerar que eran del agrado del animal

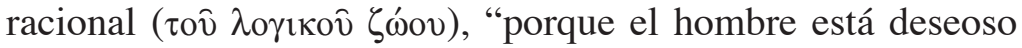
de aprender y su aprecio por los relatos es un preludio de esta cualidad [...]" (I, 2, 8). También afirma que el aprecio por los relatos induce a la audiencia a poner atención a las narraciones y a tomar cada vez más parte en ellas

debido a que el mito es un lenguaje nuevo para ellos - un lenguaje que les habla no de las cosas como son ( $\kappa \alpha \theta \varepsilon \sigma \tau \eta \kappa o ́ \tau \alpha)$, sino de otro tipo de asuntos. Y lo que es nuevo es agradable ( $\dot{\eta} \delta \dot{v}$

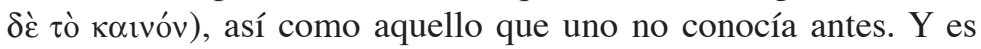
precisamente esto lo que hace que el hombre esté deseoso de aprender.

Y continúa: "Pero si a ello agregas lo maravilloso y portentoso

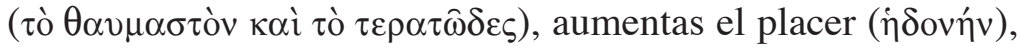
al tiempo que inspiras miedo, emociones que actúan como un encantamiento que te incita a aprender" $(1.2,8)$.

Lo que tenemos que considerar como base del género novelesco es que se trata de una narrativa de ficción, elemento que permea prácticamente toda la literatura del período y podemos suponer que responde al gusto del público. El escapismo es una demanda social, lo mismo que el tema amoroso que triunfó de diversas maneras: idealistas, pasionales, trágicas o burguesas, desde la época helenística.

Como bien sabemos, hay un estrecho nexo entre la literatura y la sociedad que la produce y a la que se dirige, "cuyas de- 
mandas, necesidades, sueños y aspiraciones refleja de alguna manera". ${ }^{2}$ Y abunda en su comentario C. Ruiz Montero, estudiosa española de la novela:

La estructura de la novela es la de un cuento maravilloso, una historia en la que lo racional se funde con la fantasía y la imaginación, como en un sueño, porque eso es lo que expresa: los sueños de una sociedad, parte de su conciencia, su búsqueda de respuestas y su deseo de felicidad y trascendencia. ${ }^{3}$

En este sentido, entonces, la novela no está desligada de las tendencias literarias de su época, como la Segunda Sofística, que reúne a una serie de exponentes de un determinado tipo de oratoria, que debía responder a las expectativas de la audiencia la cual exigía del sofista un extraordinario dominio del tema y del lenguaje, pues no se perdonaba ninguna desviación del ático clásico. La audiencia aplaudía, ovacionaba e, incluso, tocaba y besaba a los oradores; pero también gritaban, abucheaban y mantenían un silencio sepulcral. ${ }^{4}$

Había una constante demanda de la innovación, pero siempre dentro de lo establecido. En la esfera competitiva de la sofística, una medida dosis de exotismo, mezclada con respeto por los valores tradicionales, podía resultar muy exitosa.

Los sofistas frecuentemente declaraban la 'novedad' de su obra, lo mismo que la novela se presentaba como comparablemente 'novel'.5 Aunque las novelas tomaban algunos elementos de los oradores, fue central para sus ambiciones en cuanto obras literarias continuar sorprendiendo y retando a sus lectores.

Un pasaje de la obra de Plutarco Cómo un joven debe escuchar a la Poesía ejemplifica el punto:

\footnotetext{
${ }^{2}$ Cf. C. Ruiz-Montero, en G. Schmeling, 2003: 80.

${ }^{3}$ Cf. Schmeling, 2003, p. 85.

${ }^{4}$ Cf. Whitmarsh, 2005, p. 25.

${ }^{5}$ Cf. Whitmarsh, 2005, p. 87.
} 
Porque cuando el arte poética carece de la verdad, entonces princi-

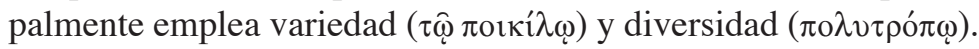
Porque el cambio súbito es lo que da a las historias los elementos

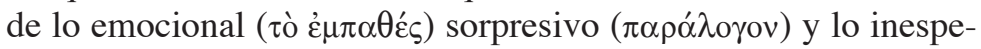
rado ( $\dot{\alpha} \pi \rho \circ \sigma \delta o ́ \kappa \eta \tau o v)$ y éstos son atendidos con un gran asombro y disfrute; pero lo simple ( $\dot{\alpha} \pi \lambda \circ \hat{\varsigma} \varsigma)$ es no-emocional $(\dot{\alpha} \pi \alpha \theta \dot{\varepsilon} \varsigma)$ y prosaico (óp

Sin duda, los novelistas siguieron al pie de la letra estos preceptos, buscando lo sorprendente, novedoso e inesperado, incluso en las novelas denominadas eróticas o más propiamente de amor y aventuras, en las que cada uno de los autores moldea los elementos básicos a voluntad, pero dentro de los cánones establecidos, a saber: los protagonistas, de belleza extraordinaria, se enamoran entre sí, se casan o quedan prometidos en matrimonio y se ven sujetos a una serie de aventuras en las cuales deben demostrar su castidad y fidelidad, a veces en situaciones extremas.

Dentro de esta trama básica, es en las aventuras donde se ve la originalidad de cada autor, que trata de sobresalir por los hechos extraordinarios que incluya en su obra.

Quizá el ejemplo más claro de esta tendencia en pos de lo maravilloso y sorprendente, sea la novela de Longo, Dafnis y Cloe, que narra el nacimiento del amor entre dos jóvenes pastores totalmente ingenuos al respecto. El marco para ello son los campos que ambos recorren con sus animales, el escenario en el que uno menos esperaría que se llevara a cabo algún tipo de prodigio.

Recojo tres situaciones que contienen hechos de carácter maravilloso. La primera se da cuando Dafnis es raptado por unos piratas - tópico de las novelas - junto con los bueyes del boyero Dorcón, y éstos se lanzan al mar al escuchar la siringa de su amo, que soplaba Cloe, con lo que propician la volcadura de la nave y, posteriormente, la salvación de Dafnis. Dice el texto: 
[...] Y los bueyes oyeron y reconocieron la melodía, y de un solo impulso, mugiendo, saltaron al mar. 2. Como el violento salto se produjo hacia un solo costado de la nave, y por el impacto de los bueyes se abrió el mar profundo, la nave se volcó y, al volverse a reunir la ola, se perdió, y los piratas cayeron de la nave no teniendo una misma esperanza de salvación. 3 Pues ellos se habían colgado sus espadas cortas y se habían vestido sus armaduras incrustadas y se habían puesto unas grebas hasta media pierna. Dafnis, por su parte, estaba descalzo, ya que pastoreaba en la llanura, y semidesnudo, pues era todavía tiempo de calor. 4. A aquellos, pues, al poco tiempo de estar nadando, los hundieron hasta el fondo sus armas. Y Dafnis se quitó fácilmente la ropa, pero se cansó de nadar, ya que antes había nadado sólo en los ríos. 5 Mas finalmente, enseñado por la necesidad lo que debía hacer, se lanzó hacia los bueyes del centro y, agarrándose con las dos manos de los cuernos de dos bueyes, era transportado en medio sin daño y sin trabajo, como si empujara un carro. Porque ni siquiera un hombre nada como un buey. Únicamente es dejado atrás por las aves acuáticas $y$, además, por los peces. Un buey no perecería nadando, a no ser que las uñas de las pezuñas, remojándose, se le cayeran. Testimonian este dicho, aún ahora, muchos lugares del mar llamados Bósforo - paso de buey $(1.30,6){ }^{6}$

Más sorprendente aún resulta la salvación de Cloe, raptada por los metimnenses, que se lleva a cabo por la intercesión de las Ninfas ante el dios Pan, y que narra el autor de la siguiente manera:

[...] Y en el punto de acabarse el día y habiéndose prolongado el deleite hasta la noche, de pronto la tierra toda pareció iluminarse con fuego, y un ruido rugiente de remos se escuchó, como si una gran flota hubiera atacado. Uno gritaba que se armaran, otro llamaba a su general y uno creía estar herido, y otro estaba tendido simulando el aspecto de muerto. Se habría creído ver una batalla nocturna, siendo que no había enemigos presentes $(2.25,3-4)$. [...] Habiendo ellos tenido una noche tal, sobrevino el día mucho

\footnotetext{
${ }^{6}$ Mi traducción.
} 
más terrible que la noche [...] los carneros y las ovejas de Cloe aullaban aullidos de lobo. Y [...] surgieron también en torno al

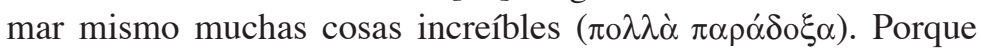
las anclas permanecían en el fondo cuando intentaban levarlas, y los remos, cuando los bajaban para remar, se rompían en pedazos. $\mathrm{Y}$ unos delfines que saltaban desde el mar golpeando con sus colas las naves, desbarataban su armazón. Se escuchaba también desde una roca que se elevaba por sobre la cima, el eco de una siringa. Pero no deleitaba como siringa, sino que atemorizaba a los oyentes como trompeta de guerra $(2.26,1-3)$.

Otra situación insólita ocurre cuando Dafnis, desesperado porque necesita dinero para poder competir por la mano de Cloe, es auxiliado por las Ninfas, las cuales le señalan un sitio donde encontrarlo. Dice el texto:

La nave fue destruida, y muchas de las cosas que había en ella. Pero una bolsa de tres mil dracmas fue arrojada por la ola y yace cubierta de algas cerca de un delfín muerto, a causa del cual ningún caminante se acerca, sino que se aleja corriendo de la fetidez de su podredumbre. 5. Pero tú acércate y recógela y luego de recogerla, entrégala. Ahora es suficiente para ti no parecer pobre; en adelante, con el tiempo, serás también rico $(3.30,4-5)$.

Uno de los autores que más buscó lo maravilloso fue Aquiles Tacio, cuya novela Las aventuras de Leucipa y Clitofonte ofrece numerosos ejemplos de situaciones inesperadas - como las varias "muertes" de la protagonista - . La primera se ofrece en un sacrificio a los dioses, durante el cual Leucipa muere aparentemente al serle enterrado un cuchillo, que luego resulta de utilería, y las vísceras que se salieron de unos animales, envueltos en una delgada piel de oveja, cosida en forma de bolsa por dentro de su ropaje $(3.15,46)$; la segunda muerte aparente se da cuando Clitofonte ve de lejos que degüellan a la joven y arrojan su cuerpo al mar, siendo que en realidad se trataba de otra mujer vestida con las ropas de Leucipa $(5.7,4-6)$. 
El episodio relacionado con el sacrificio de Leucipa es similar a situaciones que se encuentran en la novela de Loliano, las Feniciacas, de la que sólo quedan 46 fragmentos que hablan de encuentros sexuales, ceremonias que describen sacrificios humanos y orgías con disfraces que hacen pensar en fantasmas. ${ }^{7}$

Y siguiendo con esta temática que busca aterrorizar, tenemos en Aquiles Tacio una situación relacionada con la protagonista, en la que casi mata del susto a Clitofonte cuando sus amigos tocan la tapa del ataúd que ocupaba Leucipa - supuestamente muerta - y ésta responde. Dice el texto en el que Clitofonte es el narrador:

Y al tiempo que Menelao hablaba y golpeaba el ataúd dos y tres veces, también oigo desde abajo una voz muy débil. Un temblor de inmediato se apoderó de mí y vi fijamente a Menelao, creyendo que era un mago. Él abrió, al tiempo, el ataúd y Leucipa surgió de abajo; una visión terrible, oh dioses, y muy aterradora. Todo su vientre estaba abierto y vacío de intestinos. Cayéndome encima me abraza y nos estrechamos, y ambos caímos al suelo $(3.17,6-7) .^{8}$

A estos hechos extraordinarios por su invención y desarrollo, se aúna en Aquiles Tacio otra serie de situaciones en las que intervienen elementos de índole diversa, muchos de los cuales representan una mezcla de componentes de ciencia natural y paradoxografía (mirabilia): la coexistencia del fuego y del agua en una fuente de Sicilia $(2.14,6-7)$, el agua cantarina del río ibérico $(2.14,8)$ y la pesca de oro en un lago de Libia (2.14, 9-10); el ave fénix y su ritual fúnebre (3.25); y la naturaleza y crianza del elefante en la India (4. 3-5).

Entre estos mirabilia destaca el tema del amor entre diversos elementos de la naturaleza: en las plantas, en las aguas

\footnotetext{
${ }^{7}$ Cf. C. Ruiz-Montero, 2005, p. 152.

${ }^{8}$ Mi traducción.
} 
y entre los animales. En cuanto a las primeras, se habla del amor entre las palmeras:

Si la hembra está colocada lejos en el lugar de la plantación, el enamorado se seca. Entonces, el agricultor comprende la tristeza de la planta y, tras subir a un lugar elevado de la propiedad, observa hacia dónde se ha ladeado, pues se inclina siempre hacia lo que ama. Y sabiéndolo, cura la enfermedad de la planta: tomando una rama de la palmera hembra, la pone junto al corazón del macho, y reanima el espíritu de la planta; y el cuerpo que desfallecía, otra vez se reaviva y renace, gozando con el abrazo de la amada. De esta forma es la unión sexual entre las plantas $(1.17,4-5)$.

En cuanto a los animales, se habla del amor entre los reptiles, mediante la siguiente narración:

Ocurre también entre los reptiles otro misterio de amor, no sólo de uno a otro entre los que son de la misma especie, sino también entre los que son de otra especie. La víbora... se apasiona por la morena; pero la morena es otro tipo de serpiente: marina por su forma, pero pez por su modo de vida. Entonces, cuando desean unirse en matrimonio entre sí, la víbora, luego de llegar a la ribera, silba hacia el mar una señal para la morena, y ésta reconoce la señal convenida y surge de las olas. Pero no sale de inmediato hacia el novio (porque sabe que lleva la muerte en los dientes), sino que sube a una roca y espera a que el novio se purifique la boca. Así pues, viéndose uno al otro, se quedan inmóviles ambos: el amante de tierra firme y la amada de una isla. Entonces, cuando el amante ha vomitado el objeto de temor de la novia, y ella ve arrojada a tierra la muerte, en ese momento desciende de la roca, y se marcha a tierra firme, y se abraza a su amante y ya no teme sus besos $(1.18,3-5)$.

Otro novelista a considerar es Jenofonte de Éfeso, autor de Las Efesíacas quien, con un marcado regusto por lo macabro y maravilloso - como afirma su traductora en Gredos, Julia Mendoza-, acumula las trepidantes aventuras de sus pro- 
tagonistas, Habrócomes y Antía. Estos, debido a su insólita belleza, son asediados continuamente por pretendientes de los que deben defenderse y escapar.

Ofrezco aquí algunas de las peripecias que debe sufrir Antía en la búsqueda de su amado Habrócomes. Luego de salvarse de un naufragio, es capturada por una banda de bandidos comandada por Hipótoo, quienes quieren ofrecerla en un sacrificio como víctima propiciatoria - episodio que recuerda al de Leucipa en Aquiles Tacio-. El sacrificio se describe de la siguiente manera:

A la víctima que iba a ser inmolada, fuera hombre o animal, la suspendían de un árbol y alejándose de ella la acribillaban con dardos. Y creían que cuantos le daban, de ellos aceptaba el dios el sacrificio, y cuantos fallaban hacían al punto expiaciones (2. $13,2) \cdot{ }^{9}$

Interrumpido el sacrificio por la llegada del irenarca de Cilicia, de nombre Perilao, Antía se salva. Pero entonces se ve asediada por el amor de Perilao, con quien se compromete a casarse por no quedarle otro recurso. Sin embargo, como su devoción hacia Habrócomes es absoluta, pide a un médico efesio que le proporcione una pócima letal, pues prefiere morir antes que entregarse a otro hombre. A punto de tomar el veneno, pronuncia las siguientes palabras:

¡Oh alma, de mi amadísimo Habrócomes! He aquí que cumplo mi promesa y emprendo el camino que me lleva a ti, camino desdichado, pero al que me veo obligada. Recíbeme contento y dame una vida feliz allí contigo $(3.6,4)$.

Sin embargo, el brebaje sólo resulta ser un fuerte somnífero que la hace aparecer como muerta, por lo cual es enterrada con gran suntuosidad, lo que ocasiona la codicia de unos ladrones que profanan la tumba y se la llevan para ser vendida

\footnotetext{
${ }^{9}$ Traducción de Julia Mendoza, Madrid, Gredos, 1979.
} 
en Alejandría. Allí, es comprada por un rey hindú, Psamis, quien se enamora perdidamente de ella, pero acepta preservarla pura cuando Antía se dice protegida por Isis.

Luego, la caravana de Psamis es atacada y éste es muerto. Capturada Antía, es llevada a la cueva de los bandidos, uno de los cuales, enamorado de ella, quiere violentarla. Y cuando está a punto de ser forzada, la joven logra encajarle un puñal y matarlo, por lo cual se le condena a morir en una fosa profunda en donde es encerrada con varios perros salvajes. Empero, el guardián, enamorado de ella, alimenta en secreto a los perros, que se hacen mansos y así Antía se salva de una nueva muerte $(4.6,3-6)$.

Este hecho, bastante insólito, es luego recogido por el autor. El líder de los bandidos, Hipótoo, tras una serie de aventuras, hereda una fortuna de una vieja mujer con la que se desposó. Y cuando sale de compras, encuentra a Antía, a la que cree reconocer y dice:

¿No es ésta la muchacha que en otro tiempo, en Egipto, hice enterrar en una fosa para vengar la muerte de Anquíalo, y encerré perros con ella? ¿Qué cambio es éste? ¿Cómo se salvó? ¿Qué fuga de la fosa es ésta? ¿Qué es esta salvación prodigiosa? (5. $9,5)$.

Una vez salvada Antía de esta situación, se ve inmersa nuevamente en un peligro cuando Políido, pariente del gobernador de Egipto, se enamora de ella luego de rescatarla de los bandidos. Y en esta ocasión, no es él quien la amenaza, sino su esposa que, aprovechando la ausencia de aquél, la hace encerrar y encadenar y la envía a Italia con un esclavo de confianza para que la venda a un burdel $(5.5,4)$. Allí, Antía se salva, fingiéndose víctima de la epilepsia $(5.7,3)$, de la que dice haberse contagiado de la siguiente forma:

Cuando aún era niña, en una fiesta nocturna, me alejé de los míos y llegué a la tumba de un hombre recién muerto, y entonces se 
me apareció alguien que salía corriendo de la tumba e intentaba agarrarme. Yo huí y grité. El hombre era de terrible aspecto y tenía una voz más tremenda todavía. Finalmente se hizo de día y al dejarme me golpeó en el pecho ${ }^{10}$ y dijo que me había metido dentro esta enfermedad. Desde entonces me coge este mal, unas veces de una manera y otras de otra... $(5.7,7)$.

Por lo que toca a las aventuras que sufre Habrócomes, el protagonista masculino de esta novela de Jenofonte, he seleccionado las siguientes situaciones, que caen en el rubro de lo asombroso, el $\theta \alpha v \mu \alpha \sigma \tau$ ìv $\kappa \alpha i ̀ ~ \tau \varepsilon \rho \alpha \tau \omega \hat{\omega} \delta \varepsilon \varsigma$ a que hacía referencia Estrabón, como mencioné antes.

Cuando iba a ser crucificado en castigo por haber sido acusado de homicidio, Habrócomes hace una invocación al Sol quien se apiada de él. Dice el texto:

... Y se levantó de pronto una ráfaga de viento que se lanzó sobre la cruz e hizo caer la tierra que había sobre el precipicio en la que estaba enclavada la cruz. Habrócomes cayó en la corriente y fue arrastrado por ella sin que el agua le hiciera daño alguno ni las cuerdas le obstaculizaran ni las fieras le lesionaran, sino que le llevaba la corriente $(4.2,6)$.

Atrapado nuevamente, es colocado encima de una pira que lo consumiría:

[...] Y estaba ya todo preparado, la pira junto a la desembocadura del Nilo y pusieron encima a Habrócomes y encendieron debajo el fuego. Y cuando ya casi la llama iba a tocar su cuerpo, de nuevo suplicó con las pocas fuerzas que le quedaban, que le salvara de sus presentes males. Y entonces el Nilo hizo alzarse una ola y sus aguas cayeron sobre la pira y apagaron las llamas $(4.2,8-9)$.

Posteriormente, en la búsqueda de su amada Antía, Habrócomes llega a Siracusa y fija su residencia en la casa de un

\footnotetext{
${ }^{10}$ El golpe de un espectro como causante de la epilepsia aparece también en Petronio, 9 y 10. Cf. Jenofonte de Éfeso, Efesíacas, 1979, p. 300, n. 71.
} 
anciano pescador quien, para corresponder a la historia que el joven le contó sobre su amor por Antía, le narra que al morir su esposa, como la amaba profundamente, no la entierra sino que la embalsama y la conserva en su casa. Dice el texto, que mezcla la narración del pescador y la del autor:

[...] Y aquí, no hace mucho, murió Telxínoe, y yo no enterré su cuerpo, sino que lo tengo conmigo y constantemente lo beso y vivo con él.

Al mismo tiempo que hablaba condujo a Habrócomes a la habitación más recóndita de la casa y le mostró a Telxínoe, mujer ya anciana pero que [al pescador] aún le parecía bella y joven. $\mathrm{Su}$ cuerpo estaba embalsamado a la manera egipcia, pues el anciano sabía cómo hacerlo.

A ésta - dijo-, oh Habrócomes, hijo mío, siempre le hablo como si estuviera viva, y me acuesto con ella y con ella como. Y si alguna vez vengo cansado de la pesca, su vista me reconforta. Pues no me parece a mí como ahora la ves tú, sino que la imagino, hijo, como era en Lacedemonia, como cuando nuestra fuga $[\ldots](5.1,9-11)$.

Este episodio recoge ciertos elementos comunes entre los paradoxógrafos griegos, es decir escritores de hechos maravillosos, conocidos como mirabilia, que muestran cómo habían empezado a afluir contenidos un tanto extraños a sus intereses originales, que tienen que ver más con el sensacionalismo o lo fantasioso o reflejan una ingenua credibilidad en aberraciones y deformidades fisiológicas de todo tipo. Tienen así cabida historias sobre aparecidos y resucitados, anomalías sexuales, hallazgos de huesos gigantescos, casos de nacimientos monstruosos, o ejemplos de fecundidad prodigiosa y de pubertad precoz. Se ha pensado que estos contenidos podrían tener influencia etrusca o romana, donde había cierta predilección por este tipo de historias; o bien influjo oriental, desde donde habían comenzado a infiltrarse hacía ya tiempo al mundo grecorromano toda clase de creencias y supersticiones relacionadas con el mundo de ultratumba. El hecho de que este tipo de obra haya llegado 
hasta nosotros, al menos en parte, constituye seguramente un claro indicio de su popularidad y de la aceptación que esta clase de noticias y anécdotas tenía entre un público amplio, como ya señalamos anteriormente. ${ }^{11}$

\section{Conclusión}

En las páginas anteriores hemos visto cómo los distintos novelistas ofrecen en sus obras una serie de hechos insólitos o extraordinarios por sí mismos, así como otros que, sin parecerlo, son calificados como tales por su autor.

En Longo aparecen animales que responden al sonido de una siringa y saltan al mar, mostrando una insólita capacidad para nadar; así como delfines que saltan y con su cola rompen la armazón de la nave que se llevaba a Cloe y cuya ancla quedaba inmóvil, sin poder ser levada, y los remos se rompían al remar.

También encontramos en Aquiles Tacio sucesos extraordinarios en relación con Leucipa, la protagonista, de la que se ofrecen dos muertes aparentes, en una de las cuales parece resucitar y salir de su caja, lo que casi hace morir del susto a su prometido, Clitofonte. Asimismo, encontramos en este autor relatos insólitos sobre el amor en las plantas y en los animales, especialmente en el caso de dos serpientes de distinta naturaleza, que finalmente logran aparearse.

Por su parte, Jenofonte de Éfeso elabora una serie de vicisitudes a cual más increíbles de la protagonista, Antía: desde ser víctima propiciatoria en un sacrificio del que se salva milagrosamente, para caer en un matrimonio no deseado del que se libra por una pócima que, en vez de ser venenosa, resulta un poderoso somnífero; hasta, entre bandidos, lograr escapar de forma insólita de la fosa con los perros salvajes, para verse

\footnotetext{
${ }^{11}$ Cf. Paradoxógrafos griegos, pp. 165-166.
} 
nuevamente inmersa en un peligro que la lleva a un burdel, en el cual se salva de ser mancillada porque finge un ataque de epilepsia que la hace temible para quien quiera acercarse. Y ni qué decir de las aventuras de Habrócomes, el protagonista masculino quien se salva milagrosamente de ser crucificado y ahogado, y luego vive un encuentro espeluznante con un pescador que mantiene momificada en su casa a su esposa, muerta años atrás, episodio que recuerda los hechos maravillosos narrados por los paradoxógrafos griegos, como Flegón de Trales y su terrorifica historia de fantasmas y aparecidos.

Todo lo anterior demuestra cómo la novela de amor y aventuras, en su afán de entretener a un público cada vez más ávido de novedades, se inserta en las corrientes literarias de su época para lo cual incluye una serie de hechos extraordinarios y maravillosos, mirabilia, establecidos en su origen por la literatura paradoxográfica que, de Homero a la época helenística, llenó de estupor y admiración a sus oyentes.

\section{BIBLIOGRAFÍA}

AQUILES TACIO, Las aventuras de Leucipa y Clitofonte, introducción, versión y notas de Lourdes Rojas Álvarez, México, UNAM, Instituto de Investigaciones Filológicas (Serie Cuadernos XXX), 1991.

JENOFOnTE DE ÉFESo, Efesíacas, traducción y notas de Julia Mendoza, Madrid, Bibl. Clásica Gredos, 1979.

Huerta Calvo, J., "La teoría literaria de la crítica de los géneros literarios", en P. Aullón de Haro (ed.), Teoría de la crítica literaria, Madrid, Trotta, 1994.

Longo, Pastorales de Dafnis y Cloe, México, UNAM (Bibliotheca Scriptorum Graecorum et Romanorum Mexicana), 1981.

Paradoxógrafos griegos. Rarezas y maravillas, introducción, traducción y notas de Javier Gómez Espelosín, Madrid, Gredos (Biblioteca Básica Gredos, 122), 1996.

Ruiz-Montero, Consuelo, La novela griega, Madrid, Ed. Síntesis, 2005.

-, "The rise of the Greek novel", en G. Schmeling (ed.), The Novel in the Ancient World, Boston-Leiden, Brill Academic Publishers, 2003.

Whitmarsh, Tim, The Second Sophistic, Oxford, Oxford University Press, Greece \& Rome (New Surveys in the Classics, 35), 2005. 